ISBN 978-93-84468-92-7

International Conference on Issues in Education, Literature, Humanities and Social Sciences

(IELHSS-2017)

Kuala Lumpur (Malaysia) Jan. 4-5, 2017

\title{
Quality of Work Life of Chinese Teachers in Thailand
}

\author{
Dr Watchara Yisunthet, and Yiyue Chen \\ Post graduate school of Business Administration, Kasembundit University, Bangkok
}

\begin{abstract}
The purpose of this study was to study the factors affecting the quality of work life of Chinese teachers in Thailand. This study was the quantitative study with the samplings for this study were 385 people of Chinese teachers working in Bangkok by using a questionnaire as a tool. The statistics used for data analysis were percentage, mean, standard deviation, t-test, one-way Anova, and multiple regression analysis. Findings indicated that most of respondents were males, age between 26-30 years old, work experience more than 2 years, bachelor degree graduated, average monthly income between 25,001-30,000 baht, and work status as volunteer Chinese language teachers from China. The average opinions factors affecting quality of work life was in a high level consist of the following issues, work regulations in practice, personal capabilities development, a fair pay, and health and safety work environment. The hypothesis testing revealed that different personal factors including age, work experience, average monthly income, and work current status had influenced on the satisfaction of quality of work life of Chinese teachers in Thailand at significant level 0.05. And the hypothesis testing revealed that be free to offer ideas about operation in school or home for teaching on work regulations in practice, convenient location of the school or home for teaching to travel back and forth between home for living and school on health and safety work environment, and the satisfaction of salary received from teacher payroll now on a fair pay had a relationship with the satisfaction of quality of work life of Chinese teachers in Thailand at significant level 0.05 .

Recommendations of this study were that managers should focus on determining a fair pay, giving teachers an opportunity to show their knowledge and ability to function fully, giving teachers an opportunity to develop their knowledge and skills of teachers, facilitating convenient travel between accommodation and work, health and safety work environment, and determining clear work regulations to announce the general public.
\end{abstract}

Keywords: Quality of Work Life

\section{Introduction}

Economic globalization refers to the increasing interdependence of world economies as a result of the growing scale of cross-border trade of commodities and services, flow of international capital and wide and rapid spread of technologies. Chinese companies established businesses increasingly in Thailand. There are number of Chinese Industrial estates in Thailand and in same token Thai businesses want to do business with Chinese businesses in Thailand as well. Therefore, Thai companies will recruit people who can communicate in Thai and Chinese fluently and this will also include listening, speaking, reading, and writing. In addition, another requirement of the company are cultural knowledge of both Thai and Chinese. This are the opportunity for students who study abroad will have a chance to get the job when they graduate and more jobs will open for those who meet the companies requirements.

From introduction above, researcher was interested in determining quality of work life of Chinese teachers in Thailand, the results from study will be a guideline for the Chinese language teaching school to develop for a better management company. 


\section{Purpose of the Study}

The purpose of this study was to study the factors affecting the quality of work life of Chinese teachers in Thailand.

\section{Research Methodology}

1. Literature review of documents and related researches literature.

2. The questionnaire items used to operationalize each construct were developed on the basis of existing literature.

Statistical used in the data analysis were percentage, mean, standard deviation, t-test, One-Way ANOVA, and multiple regression analysis for this study.

\section{The Results of the Study}

The study of the factors affecting the quality of work life of 385 Chinese teachers in Thailand, most of respondents were males, age 26-30 years old, teaching experienced over 2 years, bachelor degree graduated, average monthly income 25,000-30,000 baht, and working statuses are volunteered Chinese language teachers from China.

Factors affecting the quality of work life of Chinese teachers in Thailand revealed that:

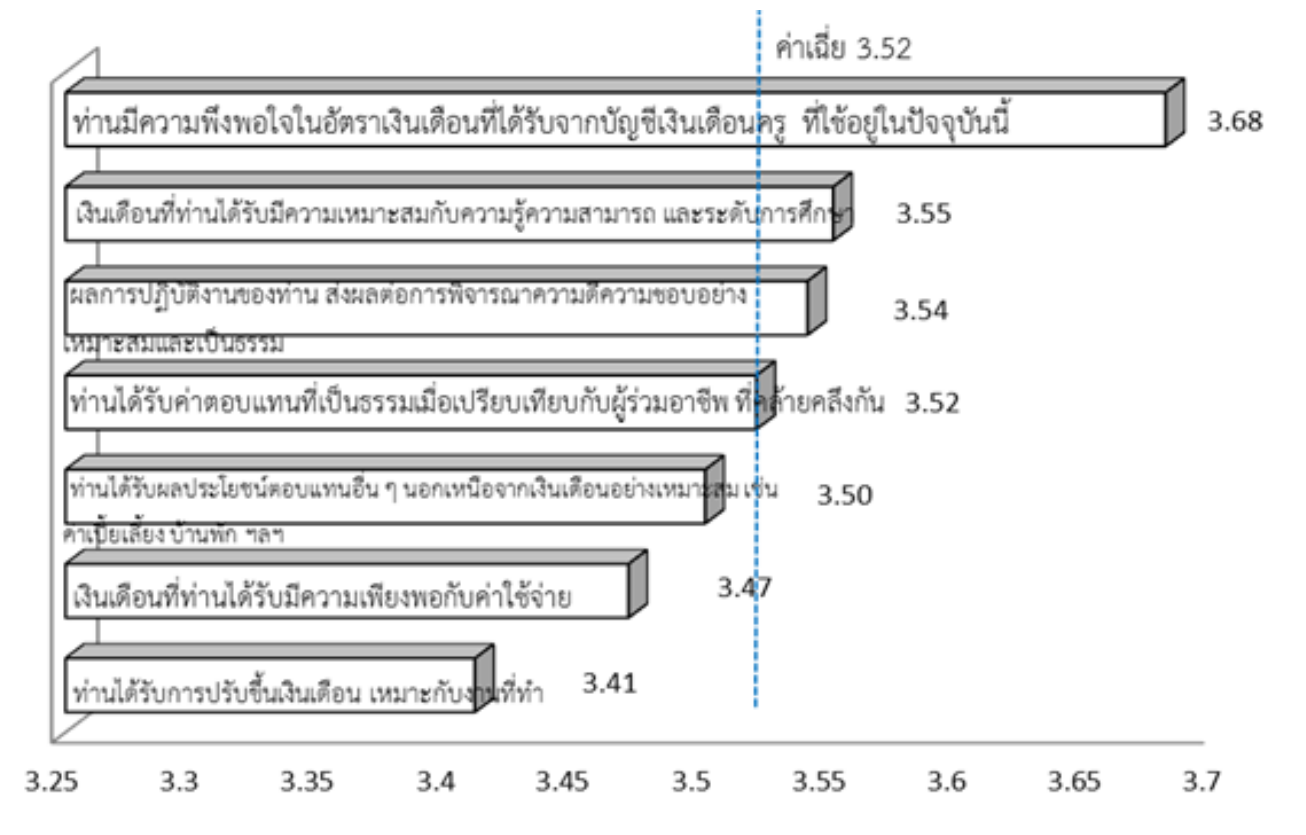

Fig. 1

From figure 1: Compensation aspect, the average picture of the opinions of compensation was at high level, such as rate of monthly salary of teachers' account $(\bar{x}=3.68)$, salary appropriate to skill level $(\bar{x}=3.55)$, promotion received from work accomplishment $(\bar{x}=3.54)$, salary comparable to others $(\bar{x}=3.52)$, any other benefit besides salary $(\bar{x}=3.50)$, salary appropriate with living expenses $(\bar{x}=3.47)$, salary adjustment appropriate to duty $(\bar{x}=3.41)$, respectively.

From figure 2: career improvement of personnel aspect, the average picture of the opinions of career improvement of personnel aspect was at high level, such as assignment according to skill level $(\bar{x}=3.74)$, express the own opinion about school $(\bar{x}=3.55)$, assignment with the challenge of your skills $(\bar{x}=3.53)$, and opportunity to suggest the solution to the problem of the school $(\bar{x}=3.45)$, respectively. In addition, the picture of the opinions of enhancing knowledge level was in medium level $(\bar{x}=3.37)$. 


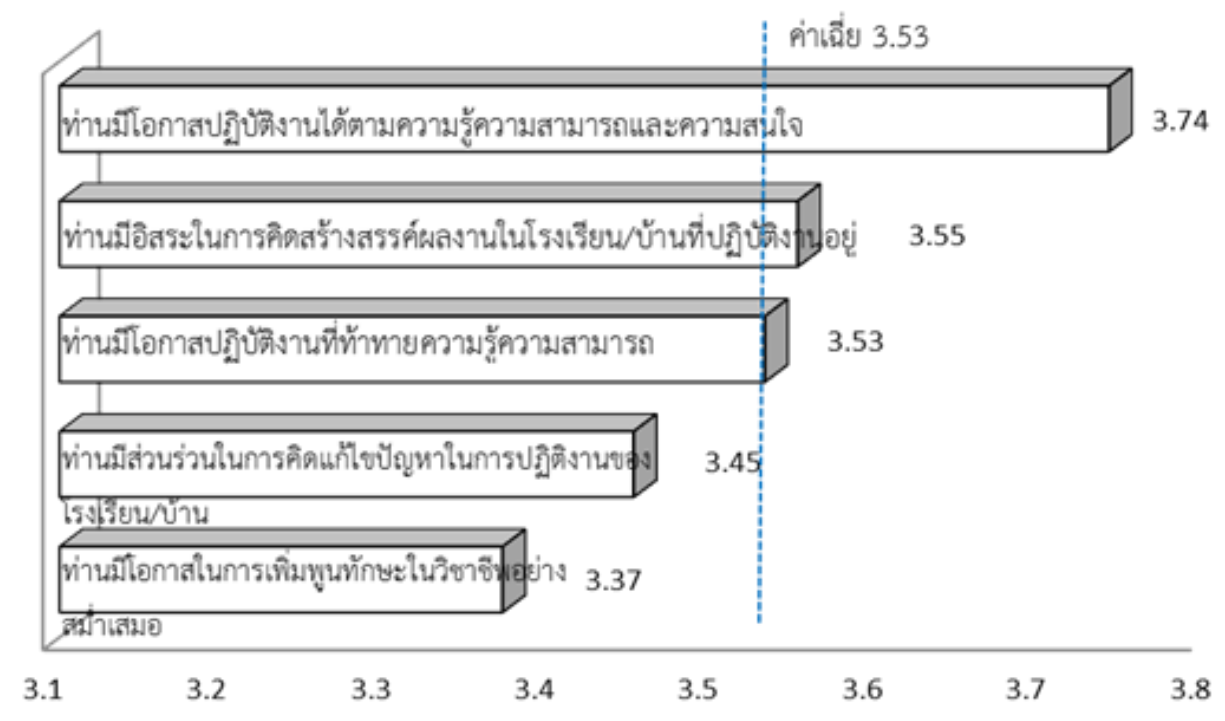

Fig. 2

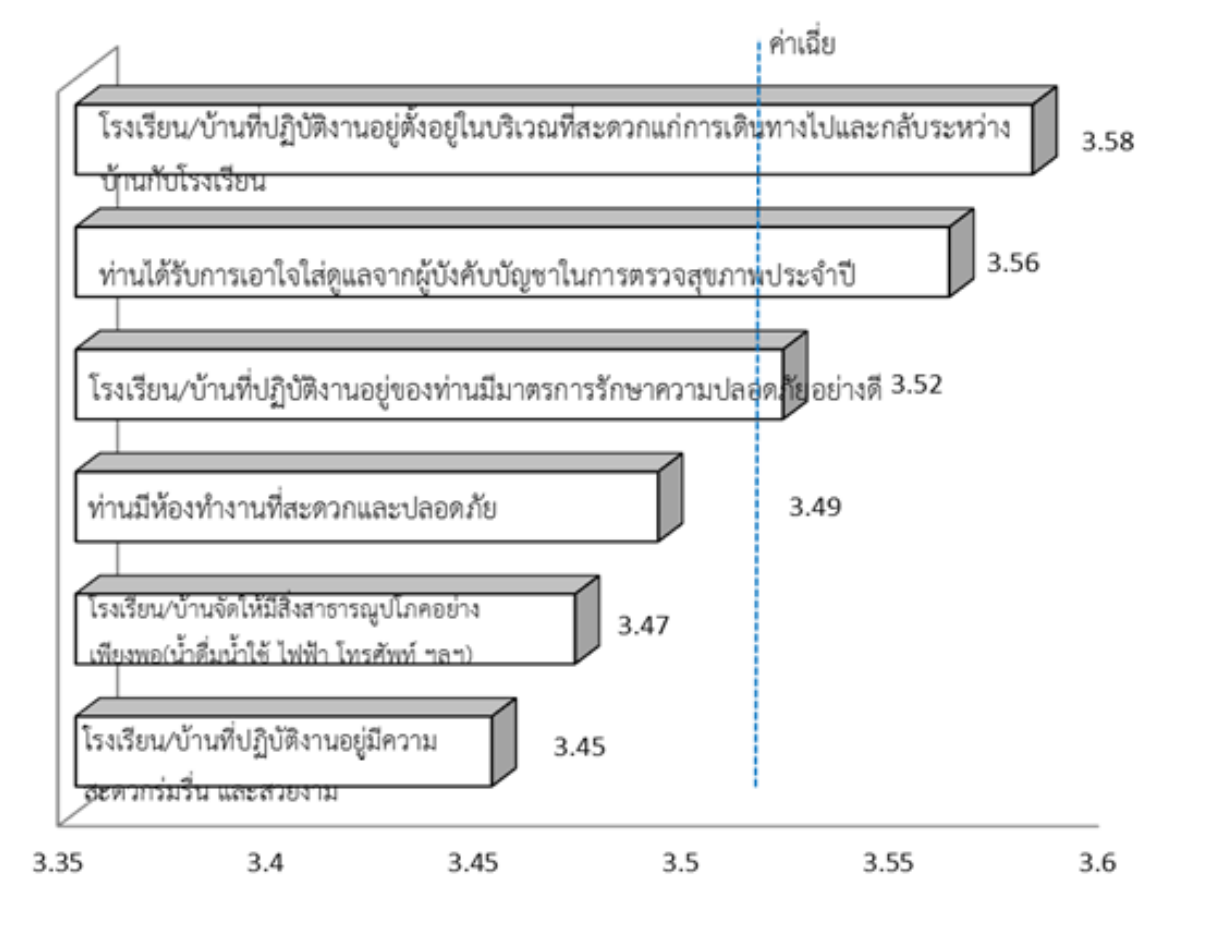

Fig. 3

From figure 3: health, safety, and hygiene of work environment aspect, the average picture of the opinions of health, safety, and hygiene of work environment aspect was at high level, such as convenient to travel to work $(\bar{x}=3.58)$, medical checkup yearly $(\bar{x}=3.56)$, security protection $(\bar{x}=3.52)$, work office with convenient and safety $(\bar{x}=3.49)$, appropriate utilities such as drinking water, electricity, telephone, etc. $(\bar{x}=3.47)$, and beautiful surrounding environment $(\bar{x}=3.45)$, respectively. 


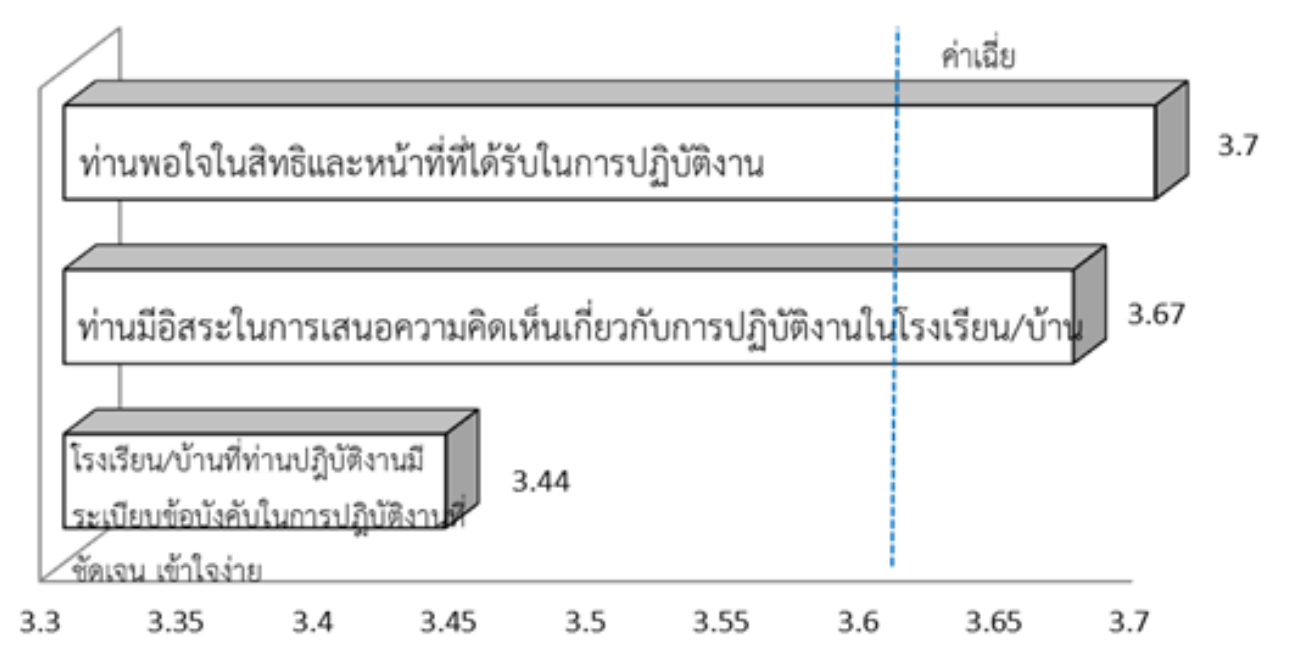

Fig. 4

From figure 4: School administrative policy aspect, the average picture of the opinions of health, safety, and hygiene of work environment aspect was at high level, such as satisfy with school policy regarding job duty $(\bar{x}=3.70)$, freedom to express your opinion regarding school management $(\bar{x}=3.67)$, simple school policy $(\bar{x}=3.44)$, respectively.

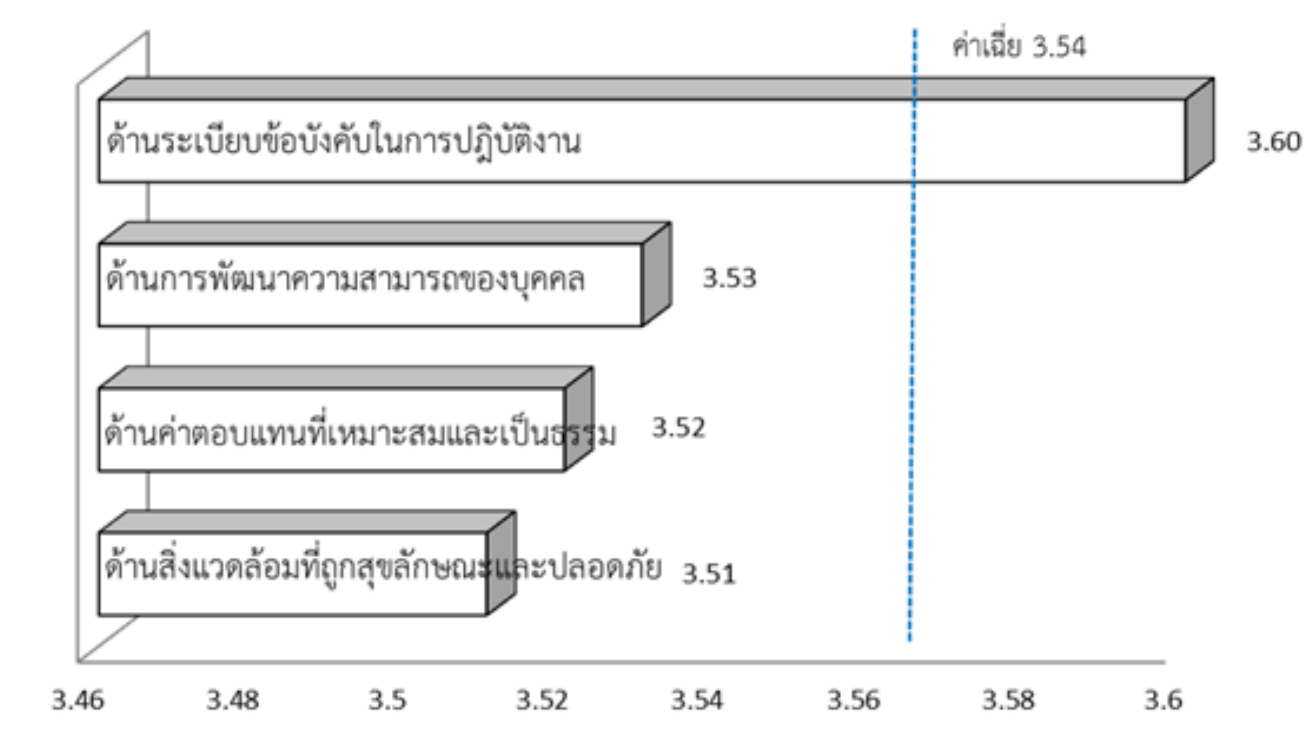

Fig. 5

From figure 5: The overall picture of the opinions of factors affecting the quality of work life of Chinese teachers in Thailand were in high level $(\bar{x}=3.54)$ consisted of, school policy of teaching duty $(\bar{x}=3.60)$, human resources development $(\bar{x}=3.53)$, appropriate compensation $(\bar{x}=3.52)$, health, safety, and hygiene $(\bar{x}=3.51)$, respectively.

\section{Summary of the Study}

The purpose of this study was to study the factors affecting the quality of work life of Chinese teachers in Thailand. This study was the quantitative study with the samplings for this study were 385 people of Chinese teachers working in Bangkok by using a questionnaire as a tool. The statistics used for data analysis were percentage, mean, standard deviation, t-test, One-Way ANOVA, and multiple regression analysis.

Findings indicated that most of 385 respondents were males, age between 26-30 years old, work experience more than 2 years, bachelor degree graduated, average monthly income between 25,001-30,000 baht, and work status as volunteered Chinese language teachers from China.

Appropriated and faired compensation, the picture of the opinions were at high level.

Human resources development, the picture of the opinions were at high level. 
Safety, health, and hygiene environment, the picture of the opinions were at high level.

Management policy aspect, the picture of the opinions were at high level.

\section{Recommendations from the Study}

Recommendations from the results of this study were that the administrative officers should focus on compensation, salary should be appropriated to skill level and their education, adjust salary suitable to their experiences, freedom of speech, be part of problem solving, medical examination for the employees yearly, safety with security environment, freedom to expression on working basis. Clearly and simply work regulation and policy.

\section{References}

[1] Davis, K. (1977). Human Behavior at Work: Organization Behavior. New York: McGraw-Hill.

[2] Delamotte, Y. \& Takezawa, S,(1984). Quality of Working Life in International Perspective. Geneva: International Labor Organization, $9(1), 2-3$

[3] Hues, Edgar F. \& Cumming, Thomas G. (1985). Organization development and change. New York: West Publishing Company.

[4] Kell, H.E.( 1995). Perceptions of the Quality of Work Life of Teachers in High Schools. Dissertation Abstracts International,55(4), 1765-A.

[5] Panagos, R.A. ( 1985). Job Satisfaction and Central Life Interests Among Education Administrator. Dissertation Abstracts International,78(80),3505-A

[6] Walton,R.E.(1973).Quality of Working Life: What is it?. Sloan Management Review,15(10). 